\title{
ECHOCARDIOGRAPHIC EVALUATION OF THE RIGHT HEART IN THE PULMONARY HYPERTENSION
}

DOI: 10.36740/WLek202009113

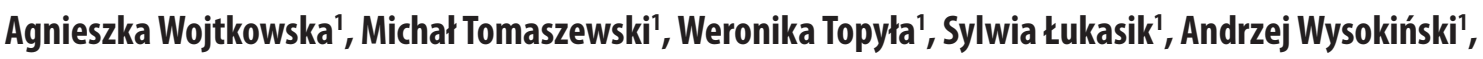 \\ Aleksandra Szopa ${ }^{2}$ \\ 'DEPARTMENT OF CARDIOLOGY, MEDICAL UNIVERSITY OF LUBLIN, LUBLIN, POLAND \\ 2DEPARTMENT OF APPLIED AND SOCIAL PHARMACY, LABORATORY OF PRECLINICAL TESTING, MEDICAL UNIVERSITY OF LUBLIN, LUBLIN, POLAND
}

\begin{abstract}
Introduction: A comprehensive assessment of right ventricular size and function, as well as evaluation of pulmonary artery pressures is an integral part of every echocardiographic examination. It is important to know the relevant guidelines but also the pitfalls of echocardiography.

The aim: To determine the significance of echocardiography in the diagnostic process, prognosis and evaluation of treatment effectiveness in pulmonary hypertension.

Review and Discussion: The gold standard for evaluation of size, ejection fraction, and stroke volume of the right ventricle is cardiac magnetic resonance. Whereas, the gold standard for the assessments of pulmonary artery pressures is right heart catheterization. However, echocardiography is the first diagnostic modality in the assessment of size and function of the right heart.

Conclusions: Echocardiographic evaluation of the right heart plays a fundamental role in the diagnostic process of pulmonary hypertension. Echocardiography is essential to predict the course of the disease and assess the treatment efficiency.
\end{abstract}

KEY WORDS: pulmonary hypertension, right heart, echocardiography

Wiad Lek. 2020;73(9 p. I):1874-1877

\section{INTRODUCTION}

The suspicion of pulmonary hypertension $(\mathrm{PH})$ is based on classic clinical symptoms and echocardiographic features that may indicate the disease. For example, transthoracic echocardiography (TTE) is used to assess the likelihood of $\mathrm{PH}$ and to evaluate treatment outcomes. However, echocardiographic examination alone is not sufficient to make a diagnosis of $\mathrm{PH}$, for which a right heart catheterization is required. Still, echocardiographic assessment of the right ventricular (RV) is a part of routine echocardiography and detailed guidelines describing this evaluation can be found in a document issued by the American Society of Echocardiography (ASE) and the European Association of Cardiovascular Imaging (EACVI) in 2015 [1].

\section{THE AIM}

The aim of the study is to determine the significance of echocardiography in the diagnostic process, prognosis and evaluation of treatment effectiveness in pulmonary hypertension.

\section{REVIEW AND DISCUSSION}

According to the ESC/ERS Guidelines for the Diagnosis and Treatment of Pulmonary Hypertension 2015, it is recommended to use maximum tricuspid regurgitation wave velocity (TRVmax), estimation by continuous wave
Doppler as the main parameter in assessing the probability of PH. Unfortunately, despite the strong correlation between TRV and the right ventricle and the systolic pressure gradient between right ventricle and right atrium (RA), pressure as established by means of Doppler measurements may be inaccurate in individual patients (e.g. patients with severe tricuspid valve regurgitation). Therefore, attention should be paid to other echocardiographic features that may enhance $\mathrm{PH}$ suspicion. Thus, to determine the probability of $\mathrm{PH}$, several additional echocardiographic parameters have been proposed. These include RV dimensions assessment, signs of RV pressure overload, RV ejection time, pulmonary artery (PA) diameter and estimated right atrial pressure (RAP). On the basis of echocardiography, the probability of low, intermediate and high $\mathrm{PH}$ can be determined [2].

In echocardiographic evaluation, it is extremely important to standardize methodology, as allowed by the knowledge of relevant recommendations. Echocardiographic techniques are constantly evolving, especially real-time three-dimensional echocardiography (3DE) and myocardial deformation imaging $[1,4]$.

The evaluation of RV dimensions and functions is complex due to its compound geometry, position just behind the sternum and the different systolic mechanism than that of the left ventricle. What is more, the right ventricle is wrapped around the left ventricle and its shape is described as a triangular pyramid [3] RV imaging should 
be performed using multiple acoustic windows and the assessment should include both quantitative and qualitative parameters. Among the parameters, which should be measured are right ventricular and right atrial dimensions, as well as right ventricular systolic function assessment, using one or a combination of the following: tricuspid annular plane systolic excursion (TAPSE), DTI-derived tricuspid lateral annular systolic velocity wave ( $\left.S^{\prime}\right)$, fractional area change (FAC) and RV index of myocardial performance (RIMP) $[1,3]$.

Additional measurements, such as RV volume and ejection fraction EF using $3 \mathrm{DE}$, can complement the above 2D measurements. To evaluate the dimensions and functions of the right ventricle, the following projections should be used: apical-four-chamber, RV-focused apical four-chamber, parasternal long axis (PLAX), short axis (SAX), left parasternal RV inflow and subcostal views. Herein, the right ventricular outflow tract (RVOT) in the proximal segment is shown in the parasternal long axis view and in the short axis view (vascular projection). Moreover, the distal RVOT is visible in SAX directly above the pulmonary aortic annulus, while the right ventricular inflow part is imaged in the parasternal view and apical four chamber view $(4 \mathrm{CH})[1,3]$.

\section{THE ECHOCARDIOGRAPHIC ASSESSMENT OF RIGHT HEART DIMENSIONS}

The recommended projection for the assessment of RV size is apical four-chamber view (4CH). However, if $4 \mathrm{CH}$ is solely focused on the left ventricle, significant variability of the right ventricle imaging results. Therefore, the linear dimensions and volume measurements may differ significantly in the same patient with a small ultrasound transducer rotation. Estimation of right ventricular dimensions is best obtained from a RV-focused apical four-chamber view. Care should be taken to visualize the entire free wall of the RV and to depict the LV apex in the central part of the imaging surface in order to obtain the largest RV basal diameter and prevent its shortening. From this projection, it is possible to measure tricuspid annular size and compare the RV dimension to the LV dimension. Basal RV linear dimension $>41 \mathrm{~mm}$ and mid-cavity RV linear dimension $>35 \mathrm{~mm}$ in RV-oriented projection indicates RV extension. The RV longitudinal dimension due to its high variability is not recommended for evaluation of RV size.

$\mathrm{RV}$ imaging is complemented by the subcostal view from which we measure the thickness of the RV front wall. Here, this measurement should be made at the top of the $\mathrm{R}$ wave and the correct value is up to $5 \mathrm{~mm}$. However, this valuation can be significantly imprecise due to significant trabeculations of the RV muscle [3]. Herein, as a result of RV pressure overload in pulmonary hypertension, the cavity is enlarged and the interventricular septum (IVS) flattens, this is the so-called paradoxical motion of IVC. The degree of IVS flattening and LV compression reflects the eccentricity index (EI). This index is the quotient of LV short axis dimension measured parallel to IVS and perpendicular to IVS in systole and diastole, respectively. Normally, this index is about 1 , but under RV pressure overload, the EI increases mainly in contraction. The size of the $\mathrm{RA}$ is measured from a $4 \mathrm{CH}$ projection from which we can determine its linear dimensions, areas and volumes. RA volumes measurements seems to be more accurate and robust for assessing RA size than linear dimensions. The ESC Guidelines for Diagnosis and Treatment of Pulmonary Hypertension include an RA area $>18 \mathrm{~cm}^{2}$ as one of echocardiographic variables suggestive of $\mathrm{PH}$ [1-3].

\section{RV SYSTOLIC FUNCTION ASSESSMENT}

The right myocardial performance index (RIMP), or Tei index, provides an indirect assessment of both systolic and diastolic RV function. When estimating RIMP, the isovolumic contraction time (IVCT), the isovolumic relaxation time (IVRT) and RV ejection time (RVET) should be measured (formula: Tei=IVCT+IVRT/RVET). RIMP can be assessed by way of two methods. The first method uses tissue Doppler echocardiography (TDE) to record tricuspid annular motion. This method allows performing measurements in one projection, during one heart cycle, which creates less risk of errors. The second method using pulsed wave Doppler (PW) to assess tricuspid inflow and ejection through the pulmonary valve. It requires measurements in two different projections, in two different heart cycles. RIMP may be falsely underestimated in conditions associated with elevated pressure in RA when IVRT is shortened. RIMP $>0.43$ with Doppler PW and $>0.54$ with DTI indicate right ventricular dysfunction [1].

Tricuspid annulus plane systolic excursion (TAPSE) is an easy to obtain and repeatable parameter indicating RV longitudinal function. This parameter depends on the longitudinal fiber function of the $\mathrm{RV}$, and it effectively reflects the global RV systolic function. TAPSE also correlates well with other parameters used in estimating RV global systolic function. Among these are: $2 \mathrm{D}$ echocardiographic RV FAC and $2 \mathrm{D}$ echocardiographic EF. The measurement is performed from a $4 \mathrm{CH} \mathrm{M}$-mode projection through the lateral part of the tricuspid annular, with optimal alignment of the cross-sectional plane. As a one-dimensional examination, it depends on the position of the transducer, so TAPSE may overestimate or underestimate the RV function. TAPSE $<17$ $\mathrm{mm}$ indicates RV systolic dysfunction $[1,5]$.

Fractional area change (FAC) is an indicator to evaluate the global RV systolic function. Estimation of the right ventricular ejection fraction in $2 \mathrm{D}$ is not possible. Therefore, an indirect method is used to assess the percentage change of $\mathrm{RV}$ cross-sectional area change during systole and diastole in a $4 \mathrm{CH}$ projection. It is important that the entire $\mathrm{RV}$, including the apex and free wall should be imaged during systole and diastole. When outlining the RV, it is crucial to incorporate the trabeculae into the RV cavity. RV FAC $<35 \%$ indicates RV systolic dysfunction [1].

DTI-derived tricuspid lateral annular systolic velocity $\left(S^{\prime}\right)$ defines the systolic function of the longitudinal fibres. This method is easy to measure, and is reliable and repeat- 
able. Furthermore, it has been shown to be well correlated with other RV systolic function parameters. $S$ ' is measured from a $4 \mathrm{CH}$ projection. It is important to keep the pulsed Doppler gate parallel to the direction of myocardium movement, in the basement segment of the free RV wall. This method has been validated against scintigraphic evaluation of the ejection fraction. The limitations of this method include the influence of heart movement on the result and dependence on the angle of the Doppler beam measurement. In patients with pulmonary hypertension, this method can be used to monitor the effectiveness of therapy and to estimate the risk $[3,12]$. An S' velocity $<9.5$ $\mathrm{cm} / \mathrm{s}$ indicates RV systolic dysfunction [1].

Longitudinal Strain, i.e. the percentage of systolic shortening of the myocardium and strain rate, i.e. the velocity of this strain generates useful parameters for estimating global and regional systolic function of the heart cavities. RV longitudinal strain is less disturbed by heart movement, but depends on the RV filling conditions, as well as the RV dimension and shape. RV longitudinal strain is measured with the RV-focused four-chamber view. RV speckle-tracking strain is affected by imaging quality, reverberation artifacts and other artifacts, as well as attenuation. Placing basal reference points too low (e.g. in the tricuspid annular) may result in false low values of basal strain. The scope of the examination should be limited to the ventricular myocardium and should exclude the pericardium. This may be difficult due to the thinner RV wall. GLS is a parameter borrowed from LV function measuring, as existing GLS measurement software was originally designed for LV and later adapted to RV. Since the contraction of the free RV wall mainly occurs in the longitudinal direction, for RV, this parameter is only marked in the longitudinal direction. The RV GLS usually refers to either the average value for the RV free wall and septal segments or to the RV free wall segments separately. According to studies, peak global longitudinal RV strain excluding IVS, has a prognostic value in various diseases affecting right heart function, such as pulmonary hypertension. Global longitudinal RV free wall strain $>-20 \%$ (i.e. $<20 \%$ of absolute value) is considered abnormal. Two-dimensional STE-derived strain, especially of free wall RV, seems to be a repeatable and feasible parameter in clinical practice. This method has been validated against the assessment of the ejection fraction by magnetic resonance imaging (MRI). The advantage of this method is also the lack of dependence on the angle of incidence of the doppler beam. Due to the need to obtain data from larger studies conducted on different software, there are currently no recommended standards for global and regional RV strain and strain rate [1-8].

Three-dimensional echocardiography enables RV volume measurements, thus overcoming the limitations of 2DE echocardiography. Recommendations for 3D RV imaging include relevant guidelines issued by EAE and ASE. Although 3D echocardiography is a technical challenge, especially in patients with poor imaging quality and significant RV enlargement, we can use it to estimate RV end-diastolic volume (EDV), end-systolic volume (ESV) and RV EF. Current data give upper standard limits for RV EDVs at $87 \mathrm{~mL} / \mathrm{m}^{2}$ for men, $74 \mathrm{~mL} / \mathrm{m}^{2}$ for women, and RV ESVs at $44 \mathrm{~mL} / \mathrm{m}^{2}$ for men and $36 \mathrm{~mL} / \mathrm{m}^{2}$ for women. However, it is noted that these data need to be verified on a larger study group. Three-dimensional RV EF evaluates the global RV systolic activity. The 3D assessment was extensively validated via MRI. Volumetric semiautomated border detection is a recommended method for assessing RV EF. The limitations of the 3D RV EF estimation include load dependence, bad sound window and irregular heart rate. RV EF is slightly larger in women than in men due to smaller ventricular volumes. An EF valuation of RV by means of the $3 \mathrm{D}$ method that is less than $45 \%$, suggests systolic dysfunction [1, 9-11].

\section{RV DIASTOLIC FUNCTION ASSESSMENT}

The cause of diastolic dysfunction of RV is myocardial fibrosis. This increases wall stiffness and thus impairs myocardial relaxation. Pulmonary hypertension is one of the conditions associated with RV diastolic dysfunction. When assessing the diastolic function, we measure the inflow through the tricuspid valve using a $4 \mathrm{CH}$ projection pulse Doppler. This dine by inserting a doppler gate at the top of the tricuspid valve leaflets, parallel to the direction of flowing blood. The measurement should be taken at the top of the exhalation. Using a tissue Doppler, we then measure the diastolic velocity of the myocardium ( $\mathrm{e}$ ' and a'), placing the doppler gate in the basal segment of the free RV wall. In addition, we assess the inflow from the hepatic vein and estimate the pressure in the right atrium and its dimension. Therein, E/A and E/e' index, early tricuspid inflow deceleration time and right atrial volume parameters are established. Based on tricuspid inflow and myocardial velocities, the following stages of RV diastolic dysfunction are distinguished:

1. impaired relaxation (when $\mathrm{E} / \mathrm{A}<0.8$ )

2. pseudonormal filling (when E/A is between 0,8 and 2,1 and $\mathrm{E} / \mathrm{e}^{\prime}>6$ )

3. restrictive $\mathrm{RV}$ filling $(\mathrm{E} / \mathrm{A}>2.1$ and deceleration time $\mathrm{E}<120 \mathrm{~ms}$ ).

To measure the size of RA, it is recommended to estimate the volume by disk summation technique (Simpson) or by applying the formula $8 / 3 \Omega^{*}\left[(\mathrm{~A})^{2} / \mathrm{L}\right.$ )] (A- area RA, $\mathrm{L}$ - longitudinal RA). The measurement is made from a $\mathrm{RV}$-focused 4Ch projection. The correct values are: $25 \pm 7$ $\mathrm{ml} / \mathrm{m}^{2}$ for men and $21 \pm 6 \mathrm{ml} / \mathrm{m}^{2}$ for women $[1,12]$.

\section{CONCLUSIONS}

Echocardiography is a very valuable tool for assessing a patient with suspected $\mathrm{PH}$. This method is also used to determine the effectiveness of therapy. Indeed, it is one of the elements in estimating prognosis in these patients. Before undertaking any related procedure, it is extremely important to know the current relevant guidelines that organize the methodologies and enable a standardization of the examination. 


\section{REFERENCES}

1. Lang RM, Badano LP, Mor-Avi V, et al. Recommendations for cardiac chamber quantification by echocardiography in adults: an update from the American Society of Echocardiography and the European Association of Cardiovascular Imaging. J Am Soc Echocardiogr 2015;28(1):1-39.e14.

2. Galiè N, Humbert M,Vachiery JL, et al. 2015 ESC/ERS guidelines for the diagnosis and treatment of pulmonary hypertension: the joint task force for the diagnosis and treatment of pulmonary hypertension of the European Society of Cardiology (ESC) and the European Respiratory Society (ERS): endorsed by: Association for European Paediatric and Congenital Cardiology (AEPC), International Society for Heart and Lung Transplantation (ISHLT) Eur Heart J 2016;37(1):67-119.

3. Rudski LG, LaiWW, Afilalo J, et al. Guidelines for the echocardiographic assessment of the right heart in adults: a report from the American Society of Echocardiography endorsed by the European Association of Echocardiography, a registered branch of the European Society of Cardiology, and the Canadian Society of Echocardiography. J Am Soc Echocardiogr 2010;23:685-713.

4. Lang RM, Badano LP, TsangW, et al. EAE/ASE recommendations for image acquisition and display using three-dimensional echocardiography. J Am Soc Echocardiogr 2012;25:3-46.

5. Giusca S, Dambrauskaite V, Scheurwegs C, et al. Deformation imaging describes right ventricular function better than longitudinal displacement of the tricuspid ring. Heart 2010;96:281-8.

6. Maffessanti F, Gripari P, Tamborini G, et al. Evaluation of right ventricular systolic function after mitral valve repair: a two-dimensional Doppler, speckle-tracking, and three- dimensional echocardiographic study. J Am Soc Echocardiogr 2012;25:701-8.

7. Hardegree EL, Sachdev A, Villarraga HR, et al. Role of serial quantitative assessment of right ventricular function by strain in pulmonary arterial hypertension. Am J Cardiol 2013;111:143-8.

8. Haeck ML, Scherptong RW, Marsan NA, et al. Prognostic value of right ventricular longitudinal peak systolic strain in patients with pulmonary hypertension. Circ Cardiovasc Imaging 2012; 5:628-36.

9. Lang RM, Badano LP, Tsang W, et al. EAE/ASE recommendations for image acquisition and display using three-dimensional echocardiography. J Am Soc Echocardiogr 2012;25:3-46.

10. Shimada YJ, Shiota M, Siegel RJ, Shiota T. Accuracy of right ventricular volumes and function determined by three-dimensional echocardiography in comparison with magnetic resonance imaging: a meta-analysis study. J Am Soc Echocardiogr 2010;23:943-53.
11. Sugeng $L$, Mor-Avi V, Weinert $L$, et al. Multimodality comparison of quantitative volumetric analysis of the right ventricle. JACC CardiovasC Imaging 2010;3:10-8.

12. Gołba KS, Waga K, Łoboda D, et al. Ocena prawej komory i zastawki trójdzielnej. In: Płońska-Gościniak E (ed). Standardy kardiologiczne 2016 okiem echokardiografisty. Warszawa: Medical Tribune Polska, 2016, pp. 85-105.

\section{ORCID and contributionship}

Agnieszka Wojtkowska - 0000-0001-9219-9763 A,B,D

Michat Tomaszewski - 0000-0001-6993-2154 ${ }^{A, D, E, F}$

Weronika Topiła - 0000-0002-3997-9952 A,D,F

Sylwia Lukasik - 0000-0002-1071-7262 ${ }^{B, D}$

Andrzej Wysokinski - 0000-0002-4562-9705 A,E

Aleksandra Szopa - 0000-0002-7756-2904 ${ }^{D}$

\section{Conflict of interest}

Authors declare no conflict of interest

\author{
CORRESPONDING AUTHOR \\ Michał Tomaszewski \\ Department of Cardiology, \\ Medical University of Lublin, Poland \\ 8 (SPSK Nr 4) Jaczewskiego str., 20-090 Lublin, Poland \\ tel: +48665828618 \\ e-mail: tomaszewskimd@gmail.com
}

Received: 06.07 .2020

Accepted: 07.09.2020

A - Work concept and design, B - Data collection and analysis, C - Responsibility for statistical analysis,

D-Writing the article, $\mathbf{E}$ - Critical review, $\mathbf{F}$ - Final approval of the article 


\title{
REVIEW ARTICLE
}

\section{HYALURONIC ACID IN ORTHOPEDICS}

\author{
Jakub Kosiński' ${ }^{1}$ Jaromir Jarecki ${ }^{1}$, Joanna Przepiórka-Kosińska ${ }^{2}$, Magdalena Ratajczak ${ }^{3}$ \\ 'CHAIR AND CLINIC OF REHABILITATION AND ORTHOPEDICS, MEDICAL UNIVERSITY OF LUBLIN, LUBLIN, POLAND \\ 2PRIVATE MEDICAL PRACTICE, LUBLIN, POLAND \\ 3EUROIMMUN POLAND A PERKINELMER COMPANY, WROCLAW, POLAND
}

\begin{abstract}
Hyaluronic acid (HA) as a compound was discovered in 1934 by Karl Meyer and John Palmer as one of the glycosaminoglycans (GAG) in the vitreous body of the bovine eye. HA occurs naturally in many organs, tissues and body fluids, and especially is presented in large quantities in articular cartilage and synovial fluid. It is a non-protein, non-sulfate glycosaminoglycan which has an important role in the physiological biomechanics of synovial fluid, there is responsible for lubrication and drug-elasticity. In the musculoskeletal system, hyaluronic acid is produced by synoviocytes, fibroblasts and chondrocytes. The concentration of hyaluronic acid decreases not only with age, but also in connection with the progression of certain diseases, for example osteoarthritis (OA). For this reason, it has been used for almost 50 years to try to alleviate and treat symptoms of $0 \mathrm{~A}$ in humans and animals. Numerous studies confirmed the beneficial effect of hyaluronic acid supplementation in OA. Patients which has intraarticular viscosupplementation of HA experience less pain and have a reduced need to take nonsteroidal anti-inflammatory drugs. Intra articular HA administration shows a low risk of local and systemic side effects while maintaining proper administration under aseptic conditions. Nevertheless, local inflammatory reactions occur, but it are most often self-limiting or do not require invasive treatment. The issue of recommending hyaluronic acid in osteoarthritis is still ambiguous and controversial.
\end{abstract}

KEY WORDS: osteoarthrosis, hailauronic acid, orthopedics, history, recomendation

Wiad Lek. 2020;73(9 p. I):1878-1881

\section{INTRODUTION}

Hyaluronic acid (HA) was isolated in 1934 by Karl Meyer and John Palmer from the vitreous body of the bovine eye. HA is a glycosaminoglycan (GAG) from the group of structurally complex linear, anionic, hetero-polysaccharides. The name "hyaluronan" appeared in 1986 to adapt the names of polysaccharides. Further studies identified its occurrence in other organs - in the joints, skin, human umbilical cord, nervous system, epithelial, connective tissue and in the rooster comb. In addition, some bacterial strains, such as Streptococcus zooepidemicus, Escherichia coli, Bacillus subtilis, are able to produce hyaluronic acid [1-3]. Other compounds belonging to this group include: keratan sulfate I and II, heparan sulfate, chondroitin sulfate, and dermatan sulfate [4].

Hyaluronic acid is the only mucopolysaccharide that is not synthesized in the Golgi apparatus, it occurs primarily in the extracellular matrix (ECM) and is composed of a repeating disaccharide unit with a molecular weight of about $400 \mathrm{Da}$. Disaccharide units can form longer chains of up to 25,000 disaccharide units with an approximate molecular weight (MW) of $107 \mathrm{Da}$ [4].

The first HA therapeutic injections were given to horses in an attempt to treat post-traumatic joint changes, which proved to be effective and has been widely used in veterinary medicine since then $[5,6]$. In humans, HA has been used since 1970 for the treatment of osteoarthritis (OA), and its use has recently expanded significantly, including outside orthopedic diseases [7-9].

\section{SYNETESIS OF HA}

There are three hyaluronic acid synthases that are responsible for its formation (Has1, Has2 and Has3). The synthesis takes place on the inside of the cell membrane and keeps individual polymer parts outside the cell [10]. It differs from the synthesis of other polymers because it correlates with the length of HA molecules and their viscosity. The difference between synthase products is the variable chain length of HA produced. Depending on the length of the chain, we can distinguish between small, medium and large polymers. The first two forms have pro-angiogenic and anti-apoptotic properties that stimulate heat shock protein (HSP) synthesis and are potent immunostimulants. On the other hand, large polymers act mainly in immunosuppressive and anti-angiogenic functions [11].

\section{HA DEGRADATION}

Enzymatic and chemical processes are important in HA catabolism. We distinguish the following hyaluronidases: HYAL1 - is an enzyme associated with lysosomes that breaks down HA into tetrasaccharides, HYAL2 - breaks down high molecular weight $\mathrm{HA}$ into $20 \mathrm{kDa}, \mathrm{HYAL}-3$ 
and HYAL-4 products occur in numerous tissues, but their participation in the process the distribution of hyaluronan is insufficiently explained [10]. HYAL-4 is known to be an isoenzyme with lower specificity, in addition to hyaluronan degradation, it also has affinity for other GAGs. The group of hyaluronidases also includes $\mathrm{PH}-20$ - sperm isozyme produced in the testes, also known as spreading factor and sperm adhesion molecule 1 (SPAM-1). Participates in the degradation of hyaluronan surrounding the egg - enabling penetration of the sperm, which can lead to fertilization. However, it is not clear at what point HA fragmentation changes from the extracellular process or on the cell surface into an endosomal or lysosomal process [4].

\section{OCCURRENCE}

HA is involved in many processes in the body. It is widely used in medicine because of its specific binding properties for a large number of water molecules. HA improves tissue hydration and resistance to mechanical damage. Interest in this compound is due to the fact that it is fully absorbable and biocompatible, which means that it is also widely available. The human body weighing $70 \mathrm{~kg}$ contains about $15 \mathrm{~g}$ of HA, which is present in many structures and tissues, including in the joints, eyes and skin. In addition to removing free radicals or rheological properties, it also plays an important role in wound healing, ovulation, fertilization, signal transduction and cancer pathophysiology [4].

\section{THE AIM}

The purpose of the article is to approximate the use of hyaluronic acid in orthopedics.

For this purpose, selected literature was reviewed.

\section{REVIEW AND DISSCUSION}

Hyaluronic acid is often used in orthopedics due to its common occurrence in synovial fluid and articular cartilage. This compound is mainly administered to patients with osteoarthritis or rheumatoid arthritis. OA is a very common disease entity, especially in the elderly population, inevitably leading to disability and a significant reduction in the quality of life due to joint mobility restrictions and chronic pain [12].

Intra-articular changes that can be seen in OA include a decrease in GAG and an increase in collagen-degrading enzymes. As a result of inflammation, there is an increased production of reactive oxygen species that degrade collagen, laminins and hyaluronic acid [13]. An important aspect of the impact of HA on joint structures is the chondroprotective effect and stimulating the synthesis of proteoglycans. High molecular weight HA reduces chemotaxis and migration of inflammatory cells, leading to a reduction in inflammation, and additionally protects against free radicals [14]. Several clinical trials have shown a slowdown in OA during HA treatment [15-17]. In addition, HA has an analgesic effect in OA $[14,18]$.

In 2008, Balogh et al. published the results of a study aimed at assessing the absorption, distribution and elim- ination of orally administered HA in rats and dogs [19]. High molecular weight technetium HA labeled HA was used for this purpose to measure HA uptake by connective tissue. Scintigraphy was performed after administration of one dose of HA-labeled, which revealed a higher concentration of compound, including in joints, salivary glands, ribs. It can be assumed that the distribution of HA in the human body looks similar [19].

In one clinical study, oral administration of HA (200 $\mathrm{mg} /$ day) for 12 months led to a reduction in knee OA symptoms in patients aged 70 and younger, combined with exercises to strengthen the quadriceps muscle of the thigh [20]. Similar results were obtained by Nelson et al. [21] also confirmed that oral HA supplementation leads to a reduction in the severity of OA symptoms. Their observations showed that oral administration of HA leads to the regulation of inflammation detected both in serum and in SF (synovial / synovial fluid) and influences the normalization of HA circulation in SF. This suggests that the effect on the normalization of HA turnover in SF slows the progression of $\mathrm{OA}$, because in preclinical models, HA turnover is associated with the severity of the disease [21].

In a randomized study, Kalman's DS et al. noted a reduced intake of acetaminophen in the study group who received oral HA. However, all authors stress that further research is needed on the impact of HA [25].

De Lucia et al. in 2020, they reviewed the systematic work comparing the effects of HA and corticosteroids (GKS) in intra-articular injection [23]. A total of $370 \mathrm{HA}$ administrations were evaluated for eight different joints (shoulder, knee, ankle, foot, elbow, wrist, fingers and toes). The assessment of treatment effectiveness was performed using various scales of function and pain disorders. In summary, each study resulted in an improvement in joint function and a reduction in pain compared to baseline [23]. Saito et al. concluded that, regardless of the joint, both HA and GKS showed similar efficacy in the treatment of rheumatoid arthritis (RA) i OA [24].

There are many HA preparations on the pharmaceutical market with different molecular weights - low (500-730 $\mathrm{kDa})$, intermediate $(800-2000 \mathrm{kDa})$ and high $(\sim 6000 \mathrm{kDa})$ for IA (articular) injection [25]. The therapeutic efficacy of these products may vary depending on the origin of HA, production method, treatment protocol, viscoelasticity, molecular weight (MW) and many other properties. The half-life of HA-containing products in the joint is significantly shorter than the duration of the therapeutic effect [26]. There is no evidence in the available publications that a particular type of HA is superior to others. However, some clinical studies show that preparations with a higher MW were more effective than those with a lower MW in relieving pain associated with $\mathrm{OA}[27,28]$. Intra-articular application of HA increases the quality of synovial fluid by increasing its viscoelastic properties. The half-life of exogenous acid is very short and ranges from 2-7 days [29]. However, some researchers have shown the presence of HA in cartilage and synovium even 28 days after administration [30]. Contrary to the above results, the long-term 
benefits of viscosupplementation, such as pain reduction and improvement of joint mobility, last from half to even a year, and may be associated with increased production of endogenous HA [31, 32].

The articular HA preparations are characterized by good tolerance and satisfactory therapeutic effects (pain reduction), which is confirmed by randomized studies [14, 33]. A very important aspect of HA is the lack of systemic effects, which reduces the risk of drug interactions, which is particularly important in patients with OA who usually have multiple comorbidities [34]. Patients under 65 with a low OA severity are a group of patients who will definitely feel the beneficial effect of HA viscosupplementation [35]. HA can be recommended for both preventive and therapeutic use of IA as an anti-inflammatory agent, reducing the severity of symptoms and modifying the course of the disease [15-17].

\section{RECOMMENDATIONS FOR USING HA IN OA}

Currently, the positions of specialist groups are divided as to the use of hyaluronic acid in the treatment of OA. According to some societies, HA is not recommended as a reliable method of treating degenerative joint changes. AAOS (American Academy of Orthopedic Surgeons) in recommendations does not recommend the use of hyaluronic acids in the treatment of knee degenerative changes [36]. ACR (American College of Rheumatology) also does not recommend the use of hyaluronic acid in the treatment of knee and hip degenerative disease [37]. However, the international organization Cochrane states that there is evidence of positive effects of hailuronic acid in degenerative changes in the knee joints [38].OARSI (Osteoarthritis Research Society International) recommends the use of hyaluronic acid for intra-articular injection in the knee, hip and polyarticular OA [39]. EUROVISCO (European Viscosupplementation Consensus Group) also recommends the use of hyaluronic acid in osteoarthritis. However, recommendations on HA viscosupplementation were divided taking into account the strength of the recommendations on a 1-9 scale:

- It is recommended to collect synovial fluid prior to injection for bacteriological examination when administering HA to any joint (recommendation 9).

- It is recommended to follow the dosing schedule - the number of HA injections and the interval between injections - as demonstrated in controlled randomized studies regardless of the joint to be treated (strength of recommendation 8 ).

- It is recommended to administer HA to the knee by the lateral patellofemoral route (strength of recommendation 9).

- It is recommended to administer HA under fluoroscopy or ultrasound control to the hip (recommendation strength 9), ankle (recommendation strength 8), shoulder (recommendation strength 8), metacarpal I (recommendation strength 8), and to the temporomandibular joint ( strength of recommendation 8)

- Injections with the help of ultrasound on fluoroscopy are recommended (strength of recommendation 9) [40].

\section{CONCLUSION}

The impact of the hyaluronic acid used for delivery still raises controversy in the orthopedic circle, but many years of research prove the beneficial effects of this type of injection into joints in the treatment of degenerative changes. The studies cited above show the benefits of administering $\mathrm{HA}$ to OA patients, especially regarding the reduction of pain experienced by patients. Some results also suggest improving a small degree of joint mobility, but this may be due to a reduction in the pain component felt. HA monotherapy does not lead to the regeneration of joint surfaces, however, it contributes to the reduction of inflammation in $\mathrm{OA}$ and better nutrition of the remaining articular cartilage. Indirectly, the beneficial effect of HA in OA also consists in reducing the amount of nonsteroidal anti-inflammatory drugs taken by patients. Intra-articular injection of HA shows a low risk of systemic and local adverse effects when administered under aseptic conditions and with proper administration. Nevertheless, local inflammatory or allergic reactions occur, which, however, usually do not require invasive methods of treatment. The issue of recommending $\mathrm{HA}$ administration in osteoarthritis is still ambiguous, and the decision to use this type of therapy as supportive therapy for OA should be made in consultation with the patient.

\section{REFERENCES}

1. Sugahara K, Schwartz NB, Dorfman A. Biosynthesis of hyaluronic acid by Streptococcus. J Biol Chem. 1979;254:6252-6261.

2. Yu HM, Stephanopoulos G. Metabolic engineering of Escherichia coli for biosynthesis of hyaluronic acid. Metab Eng. 2008;10:24-32.

3. Liu L, Liu Y, Li J et al. Microbial production of hyaluronic acid: current state, challenges and perspectives. Microb Cell Fact. 2011;10:99. doi:10.1186/1475-2859-10-99.

4. Gupta RC, Lall R, Srivastava A et al. Hyaluronic Acid: Molecular Mechanisms and Therapeutic Trajectory. Front Vet Sci. 2019;6:192. doi:10.3389/fvets.2019.00192.

5. BalazsEA. Sodium hyaluronate and joint function. JEVS.1985;5:217-228.

6. Balasz EA, Laurent TC. New applications for hyaluronan. In: Laurent TC. editor. The Chemistry, Biology, and Medical Applications of Hyaluronan and its Derivatives. London: Portland Press;1998, pp. 325-36.

7. Liang J, Jiang D, Noble PW. Hyaluronan as a therapeutic target in human diseases. Adv Drug Deliv Rev.2016;97:186-203.

8. Jiang D, Liang J, Noble PW. Hyaluronan as an immune regulator in human diseases. Physiol Rev. 2011;91:221-264.

9. Groß D, Childs M, Piaton JM. Comparison of $0.2 \%$ and $0.18 \%$ hyaluronate eye drops in patients with moderate to severe dry eye with keratitis or keratoconjuctivitis. Clin Opthalmol. 2017;11:631-638.

10. Prehm P. Release of hyaluronate from eukaryotic cells. Biochem J.1990;267:185-189.

11. Slevin M, Krupinski J, Gaffney J et al. Hyaluronan mediated angiogenesis in vascular disease: uncovering RHAMM and CD44 receptor signaling pathways. Matrix Biol. 2007;26:58-68.

12. Gupta S, Hawker GA, Laporte A et al. The economic burden of disabling hip and knee osteoarthritis (OA) from the perspective of Individuals living with this condition. Rheumatology. 2005;44:1531-1537.

13. BatesEJ, HarperGS, LowtherDA etal. Effect of oxygen-derived reactive species on cartilage proteoglycan-hyaluronate aggregates. Biochem Int. 1984;8:629-637.

14. Moreland LW. Intra-articular hyaluronan (hyaluronic acid) and hylans for the treatment of osteoarthritis: mechanisms of action. Arthritis Res Ther. 2003;5:54-67. 
15. Kuroki K, Cook JL, Kreeger JM. Mechanisms of action and potential uses of hyaluronan in dogs with osteoarthritis.J AmVetMed Assoc. 2002;221:944-950.

16. Carapeba GOL, Cavaleti P, Nicácio GM et al. Intra-articular hyaluronic acid compared to traditional conservative treatment in dogs with osteoarthritis associated with hip dysplasia. Evid-Based Compl Altern Med. 2016;2016:20726921. doi:10.1155/2016/2076921.

17. Neustadt D, Caldwell J, Bell M et al. Clinical effects of intraarticular injection of high molecular weight hyaluronan. (Orthovisc) in osteoarthritis of the knee: A randomized, controlled, multicenter trial. J Rheumatol. 2005;32:1928-1936.

18. Moore AR, Willoughby DA. Hyaluronan as a drug delivery system for diclofenac: a hypothesis for the mode of action. Int J Tissue React. 1995;17:153-156.

19. Balogh L, Polyak A, Mathe D et al. Absorption, uptake and tissue affinity of high-molecular-weight hyaluronan after oral administration in rats and dogs. J Agric Food Chem.2008;56:10582-10593.

20. Tashiro T, Seino S, Sato T et al. Oral administration of polymer hyaluronic acid alleviates symptoms of knee osteoarthritis: a double-blind, placebo-controlled study over a 12-month period. Scientif World J.2012;2012:167928.doi:10.1100/2012/167928.

21. Nelson FR, Zvirbulis RA, Zonca B et al. The effects of an oral preparation containing hyaluronic acid. (Oralvisc ${ }^{\oplus}$ ) on obese knee osteoarthritis patients determined by pain, function, bradykinin, leptin, inflammatory cytokines, and heavy water analysis. Rheumatol Int. 2015;35:43-52.

22. Kalman DS, Heimer M, Valdeon A et al.Effect of a natural extract of chicken combs with a high content of hyaluronic acid (Hyal-Joint ${ }^{\circledR}$ ) on pain relief and quality of life in subjects with knee osteoarthritis: a pilot randomized double-blind placebo-controlled trial. Nutr J. 2008;7: 3. doi:10.1186/1475-2891-7-3

23. De Lucia 0, Murgo A, Pregnolato F et al. Hyaluronic Acid Injections in the Treatment of Osteoarthritis Secondary to Primary Inflammatory Rheumatic Diseases: A Systematic Review and Qualitative Synthesis. Adv Ther. 2020;37(4):1347-1359.

24. Saito S, Momohara S, Taniguchi A et al. The intra-articular efficacy of hyaluronate injections in the treatment of rheumatoid arthritis. Mod Rheumatol. 2009;19:643-651.

25. Berenbaum F, Grifka J, Cazzaniga Set al. A randomized, doubleblind, controlled trial comparing two intra-articular hyaluronic acid preparations differing by their molecular weight in symptomatic knee osteoarthritis. Ann Rheum Dis. 2012;71:1454-1460.

26. Waddell DD. Viscosupplementation with hyaluronans for osteoarthritis of the knee. Clinical efficacy and economic implications. Drugs Aging. 2007;24:629-642.

27. Wobig M, Bach G, Beks Pet al. The role of elastoviscosity in the efficacy of viscosupplementation for osteoarthritis of the knee: a comparison of Hyalgan G-F 20 and a lower-molecular weight hyaluronan. Clin Ther. 1999;21:1549-1562.

28. Santilli V, Paoloni M, Mangone $M$ et al. Hyaluronic acid in the management of osteoarthritis: injection therapies innovations. Clin Cases Miner Bone Metab. 2016;13:131-134.

29. Bagga $H$, Burkhardt D, Sambrook $P$ et al. Longterm effects of intraarticular hyaluronan on synovial fluid in osteoarthritis of the knee. J Rheumatol. 2006;33(5):946-950.

30. Stitik TP, Kazi A, Kim JH. Synvisc ${ }^{\circledR}$ in knee osteoarthritis. Future Rheumatol.2008;3(3):215-222.

31. Pal S, Thuppal S, Reddy KJ, et al. Long-term (1-year) safety and efficacy of a single 6-mL injection of Hylan G-F 20 in Indian patients with symptomatic knee osteoarthritis. Open Rheumatol J. 2014;8:54-68.
32. Campbell KA, Erickson BJ, Saltzman BM, et al. Is local viscosupplementation injection clinically superior to other therapies in the treatment ofosteoarthritis of the knee: a systematic review of overlapping meta-analyses. Arthroscopy. 2015;31:2036-2045.

33. Altman RD, Moskowitz R. Intraarticular sodium hyaluronate (Hyalgan) in the treatment of patients with osteoarthritis of the knee: a randomized clinical trial. Hyalgan Study Group. J Rheumatol. 1998;25:2203-2212.

34. Szabó A, Zelkó R, Antal I. Treatment of rheumatic diseases with intraarticular drug delivery systems. Acta Pharm Hung.2011;81:77-86.

35. Wang CT, Lin J, Chang CJ et al. Therapeutic effects of hyaluronic acid on osteoarthritis of the knee: A meta-analysis of randomized controlled trials. J Bone Joint Surg Am.2004;86-A:538-45. doi:10.2106/00004623200403000-00012.

36. Jevsevar DS. Treatment of osteoarthritis of the knee: evidence-based guideline. J Am Acad of Orthop Surg. 2013;21:571-576.

37. Hochberg MC, Altman RD, April KT et al. American College of Rheumatology 2012 recommendations for the use of nonpharmacologic and pharmacologic therapies in osteoarthritis of the hand, hip, and knee. Arthritis Care Res. 2012;64:465-474.

38. Bellamy N, Campbell J, Welch V et al. Viscosupplementation for the treatment of osteoarthritis of the knee. The Cochrane Library 2006.

39. Bannuru RR, Osani MC, Vaysbrot EE et al. OARSI guidelines for the nonsurgical management of knee, hip, and polyarticular osteoarthritis. Osteoarthritis Cartilage. 2019;27(11):1578-1589.

40. Conrozier T, Monfort J, Chevalier X et al. EUROVISCO Recommendations for Optimizing the Clinical Results of Viscosupplementation in Osteoarthritis. Cartilage. 2020;11(1):47-59.

\section{ORCID and contributionship:}

Jakub Kosiński- 0000-0003-1700-0317 A,B,C,D,F

Jaromir Jarecki-0000-0002-6866-3850 A,C,E

Joanna Przepiórka-Kosińska- 0000-0001-9073-876X ${ }^{A, B, D, E}$ Magdalena Ratajczak-0000-0002-2864-4305 D

\section{Conflict of interest}

Magdalena Ratajczak is an employee of Euroimmun Poland a Perkinelmer Company.

\section{CORRESPONDING AUTHOR Jakub Kosiński}

Chair and Department of Rehabilitation and Orthopaedics, Medical University in Lublin, , (SPSK Nr 4) Jaczewskiego 8 str, 20-090 Lublin, Poland tel: 503109294

e-mail:kuba.kosinski@gmail.com

Received: 06.07 .2020

Accepted: 07.09 .2020

A - Work concept and design, B - Data collection and analysis, C - Responsibility for statistical analysis, D-Writing the article, $\mathbf{E}$-Critical review, $\mathbf{F}$ - Final approval of the article 


\title{
ISCHEMIC SPINAL CORD INJURY FOLLOWING AORTIC STENT GRAFT IMPLANTATION - CASE STUDY
}

D0l: 10.36740/WLek202009115

\author{
Magdalena Sobiech ${ }^{1}$, Karolina Turżańska ${ }^{1}$, Jaromir Jarecki' ${ }^{1}$ Aleksandra Szopa ${ }^{2}$ \\ 'CHAIR AND DEPARTMENT OF REHABILITATION AND ORTHOPAEDICS, MEDICAL UNIVERSITY OF LUBLIN, LUBLIN, POLAND \\ 2DEPARTMENT OF APPLIED AND SOCIAL PHARMACY, LABORATORY OF PRECLINICAL TESTING, MEDICAL UNIVERSITY OF LUBLIN, LUBLIN, POLAND
}

\begin{abstract}
SUMMARY
Morbidity and mortality associated with aortic aneurysm remains high. Aneurysms involving the thoracic and lumbar part of the aorta (TAAA) are particularly burdened with mortality. They are also one of the biggest challenges that vascular surgeons can face. Despite several dozen years of progress in surgical techniques, as well as the constant development of accompanying methods of spinal protection, ischemic spinal cord injury with subsequent paresis or pareresis is still one of the most serious complications of both open and closed surgical treatment of aortic aneurysms. Ischemic complications of the spinal cord occur immediately after the procedure, when the patient wakes up with a neurological deficit (according to some authors within the first day after the procedure) or in a deferred manner. In the case of open surgery, immediate damage is more common, in the case of endovascular surgery - deferred. Factors such as low blood pressure, arrhythmias, cardiovascular failure, sepsis and anemia due to anemia contribute to an increased risk of deferred complications. The rehabilitation of a patient with limb paralysis as a consequence of vascular spinal injury is laborious and requires a comprehensive approach. Proper treatment and prompt intervention in the form of rehabilitation is a great therapeutic challenge.

The aim of the paper was to present the importance of the ischemic injuries of spinal cord following aortic stent graft implantation through a case report.
\end{abstract}

KEY WORDS: ischemic spinal cord injury, aneurysm, aorta, graft

Wiad Lek. 2020;73(9 p. I):1882-1887

\section{INTRODUCTION}

Despite several dozen years of progress in surgical techniques, as well as constant development of accompanying methods of spinal protection, ischemic spinal cord injuries with subsequent paresis or pareresis are still one of the most serious complications of both open and closed surgical treatment of aortic aneurysms. The risk of ischemic spinal injury according to various sources ranges from $2-10 \%$ and is similar for both open and endovascular surgical techniques [1]. It is recognized that the pathogenesis of spinal injury during the procedure is multifactorial, however, its mechanism has not yet been fully explained. The two most frequently considered theories are insufficient remodeling of collateral circulation designed to maintain the life of the spinal cord and closure of nutrient vessels caused mechanically by the operator during clamping, with graft material or other (e.g., material derived from atherosclerotic plaque) [2]. Morbidity and mortality associated with aortic aneurysm remains high. In the United States, death associated with aortic aneurysm is estimated to be 14 th among people over 55 and 17th among all age groups, European statistics remain equally high. Aneurysms involving the thoracic and lumbar part of the aorta (TAAA) are particularly burdened with mortality. They are also one of the biggest challenges that vascular surgeons can face.

\section{ABDOMINAL AORTIC ANEURYSMS (AAA)}

The incidence of abdominal aortic aneurysms increases with age [3]. In addition to age, risk factors for the development of an aneurysm in this area include male sex, smoking [4-8] hypercholesterolemia and hypertension [5, $9,10]$ as well as family history of the disease. It is assumed that the risk of abdominal aortic aneurysm increases by $6 \%$ for 10 years after exceeding the age of 65 [11]. In animal models, the association of initiation and development of abdominal aortic aneurysms with inflammatory processes is noteworthy. This is confirmed by human studies [12, 13]. Also, diseases associated with a high inflammatory response such as asthma or psoriasis - are associated with a high percentage of abdominal aortic aneurysms [14,15]. Animal models also show the important role that the renin angiotensin system plays in the development of AAA [16]. Interestingly, the occurrence of diabetes reduces the risk of developing AAA [17], and high hemoglobin A1C levels is inversely correlated with the development of abdominal aortic aneurysms [18].

\section{THORACIC AORTIC ANEURYSMS}

Thoracic aneurysms (TAAs) are less common than those located in the lumbar region. Their incidence reaches 
6-10 cases per 10,000 population. In contrast to lumbar aneurysms, they are approximately $20 \%$ associated with the $98 \mathrm{LU}$ pacific genetic variants. Among the mutations associated with this type of aneurysms, min. mutations of fibrillin-1 (Fbn 1 ) and changes associated with the TGF-beta receptor 99-103. This has also been confirmed by experimental animal studies. In addition to genetic factors, the development of aortic valve aortic valve is associated with the development of thoracic aortic aneurysms [19].

\section{THORACOLUMBAR ANEURYSMS:}

Thoracolumbar aneurysms (TAAA) are defined as $1.5 \mathrm{x}$ dilatation of the thoracic and lumbar part of the aorta compared to its initial diameter. Most often occur in old age (average age of 66) [2]. Although lumbar and descending aortic aneurysms are more common than these, descending and thoracolumbar aneurysms are gaining in importance. This is not only related to the expansion of diagnostic options - enabling detection, but also to the permanent aging of societies. Their incidence reaches a total of over 16 cases in 10,000 men and over 9 in 10,000 cases in the female population [20]. The natural course leads to a constant widening of the aneurysm size up to the rupture of the vessel wall. TAAAs are classified according to the division proposed by Crawford [1]. The four-grade classification is based on anatomical coverage. Type 1 (25\%) covers most of the descending thoracic aorta, from the left subclavian artery (LSA) to the renal arteries. Type II (29\%) can start anywhere below LSA and extends to the splitting of the aorta. Type III (23\%) starts below Th6 and can reach up to split. Type IV (23\%) is limited to the abdominal part below the diaphragm. The Crawford classification correlates with the difficulty of performing the procedure as well as the risk of complications. Type II is associated with the highest rates of death, paraplegia, renal failure and other complications [2].

\section{SURGICAL TREATMENT}

\section{OPEN SURGICAL TREATMENT}

Since the 1950s it has been the gold standard of TAAA treatment. Initially, homographs were used in the treatment, followed by vascular prostheses [21, 22]. Stanley E. Crawford began the era of modern TAAA treatment. His pioneering surgical technique resulted in a decrease in mortality during procedures from 26 to $8 \%$ and a risk of paraplegia to $16 \%$ (in a series of over 1,500 procedures performed) [2]. Modern data give mortality ranging from 6.2 to over $20 \%$ depending on the experience of the center, the surgeon conducting the procedure and the situation in which it is performed (elective or emergency surgery) [23, 24]. In the analysis of 797 planned open TAAA procedures performed in California, mortality within 1 month was $19 \%$, within 1 year 31\% [25]. The consequence of treatment is also often prolonged hospitalization and long, painstaking rehabilitation. Contraindications for open procedures are: advanced age, serious pulmonary diseases, circulatory failure, renal failure, complicated aortic morphology and a high risk of aneurysm wall rupture. In studies analyzing the consequences of endovascular procedures performed in patients disqualified from open surgery due to excessive operational risk, mortality during the first month was 4.8-5.5\%, and complications in the form of permanent paraplegia in $2.7-4 \%)[26,27]$. This shows that endovascular procedures give results comparable to those achieved during open procedures performed in highly specialized centers, even taking into account that in the analyzed cases the most burdened disqualified patients from open procedures were taken into account.

\section{ENDOVASCULAR SURGERY}

Precursors of endowasculation were scientists from Eastern Europe, who in the 1980 s provided traumatic injury to the thoracic aorta with a stentograft of their own design [28] a few years later, the same team undertook to stent an abdominal aortic aneurysm from the same access, but the attempt proved unsuccessful. This obstacle was overcome in 1991 [29]. A few years later, the procedures began to be applied successfully with regard to the thoracic aorta [30]. Since then, constant technical progress has been noted in both modernizing operational techniques and the equipment used at the time. In Poland in 1998, the first surgery to establish a stentograph was made by Professor M. Szczerbo-Trojanowska in Lublin [31]. It is a safe procedure, which does not require closing the vessel lumen and virtually no blood loss ( $\max 200 \mathrm{ml})$. Today, this is the standard procedure in the treatment of acute and chronic thoracic aortic aneurysms. This treatment eliminates the dissection site, restores normal blood flow to the tissues, protects the vessel walls and excludes the aneurysm from the bloodstream. It is also used in emergency or traumatic situations, where there is no possibility of surgical treatment because of the patient's general health [32-34]. The main limitation in the use of endovascular procedures is the need to anchor grafts to the healthy wall of the vessel, without closing the vessels departing from the aorta. In the case of aneurysms involving the aortic orifices, special graft, fenestrated or branched models must be used [35]. In a large study evaluating the effect of TAAA treatment with branched stents. Studies conducted on 185 patients showed a good technical effect in $98 \%$, mortality within the first month at $9 \%$ and complications in the form of vascular trauma in 6\% [36].

\section{ISCHEMIC SPINAL INJURIES}

Ischemic spinal injury is a complication dramatically affecting the quality of life of patients. In addition to dramatic changes in quality of life, this complication also increases the risk of death for affected patients [37]. In a study comparing patients affected and not affected by a spinal cord injury in over 570 patients undergoing surgery for aneurysm, a significantly higher first-month mortality (23 to 8\%) was observed, lower 
5-year survival (25 to $51 \%$ ) in patients with perioperative trauma spinal cord [38]. This is confirmed by the results of studies comparing patients with transient spinal dysfunction to those with definitive damage [39]. Blood supply to the core and mechanisms of damage during aneurysm surgery:

The frequency of spinal cord vascular injuries is due to its blond supply system. The spinal cord is provided with vertebral artery branches: the anterior vertebral artery supplying the motor areas of the spinal cord and the two posterior spinal arteries supplying its sensory areas. The anterior spinal artery is supplied by segmental branches of the aorta by radicullar medullary arteries. During aneurysmal surgery, many of these vessels may be lost, resulting in immediate or delayed ischemic injury. During open surgery, it is necessary to use a cross clamp to temporarily reduce blood flow to the spinal cord to allow surgery. In addition to reducing blood supply to the spinal cord, it contributes to an increase in venous pressure and cerebrospinal fluid, ultimately contributing to ischemia and the release of neurotoxic substances. Secondary restoration of circulation (revascularization) may, contrary to appearances, worsen this condition by reperfusion injury [40]. During endovascular surgery, the mechanism of injury is the segmental artery closure by a stentographer, especially in the absence of revascularization techniques available during open surgery. Mechanisms such as vascular embolization, hemodynamic destabilization with subsequent hypotension, and insufficient collateral circulation are also considered [39, 41]. Many strategies have been developed to prevent this complication from Cerebrospinal fluid drainage and permissive hypertension as binders. Security factors also include proper postoperative care with monitoring to prevent hemodynamic disorders and the operator's knowledge of not only the mechanisms of spinal perfusion but also the possibility of collateral circulation with subclavian and hypogastric artery, and thus ensuring their activity, especially for more extensive procedures and early intraoperative reperfusion of the lower limbs and pelvis. Ischemic complications of the spinal cord occur immediately after the procedure, when the patient wakes up with a neurological deficit (according to some authors within the first day after the procedure) or in a deferred manner. In the case of open surgery, immediate damage is more common, in the case of endovascular surgery - deferred [42]. Factors such as low blood pressure, arrhythmias, cardiovascular failure, sepsis and anemia due to anemia contribute to an increased risk of delayed complications. The rehabilitation of a patient with limb paralysis as a consequence of vascular spinal injury is laborious and requires a comprehensive approach. Proper treatment and prompt intervention in the form of rehabilitation is a great therapeutic challenge.

\section{THE AIM}

The aim of the paper was to present the importance of the ischemic injuries of spinal cord following aortic stent graft implantation through a case report.

\section{A CASE REPORT}

A 66-year-old patient was admitted to the Vascular Surgery Department of the Independent Clinical Hospital No. 4 in Lublin due to an aneurysm just above the T-Branch stent graft implanted in May 2019 due to dissection of the thoracic-abdominal aorta involving the visceral and renal vessels. After surgery in 2019, a complication of generalized sepsis occurred. In 1999, the patient underwent laryngectomy due to larynx cancer. In February 2010, based on the clinical picture and angiography, the patient was qualified for re-implantation of the stentograft due to the progressive aortic dissection above the prosthesis. In addition, the patient suffered from hypertension and gout. He was in full logical contact during the admission to the ward. The functional condition was assessed as very good. Before the surgery, in the initial functional assessment (balance and gait assessment - Tinnetti scale) a maximum of 10 points was obtained (full physical fitness, independence and no risk of falls). In the Barthel scale the maximum of 100 points was obtained, indicating complete independence in everyday life activities. The surgery was carried out correctly. In the postoperative period, complications in the form of deep flaccid paralysis of the left lower limb and deep paresis of the right lower limb occurred. In the following days there was a neurological and neurosurgical consultation and CT scan of the lumbosacral and thoracic spine (Fig.1). The study showed degenerative changes of the spine, protrusion of the L4/5 disc, no signs of bleeding into the spinal canal. The clinical picture supported vascular spinal cord injury in the area of anterior spinal artery vascularisation. In the neurological assessment a negative Babinski reflex, no tendon reflexes, no pain sensation were found, with a untouched skin sensation. In the following days the patient was qualified and transferred to the Department of Neurological Rehabilitation in order to continue treatment and rehabilitation. Upon admission to the Rehabilitation Ward the patient was lying down, unable to sit down on his own, barely maintained a sitting position with his legs down outside the bed when seated passively. On the Barthel scale 15 points was obtained so the patient's condition was assessed as "very severe" (required help in most everyday activities). On the Tinnetti scale, he scored 0 points. In Lovett muscle strength assessment, the lower left limb was rated 0 - no movement, there was a trace of movement in lower right limb in the hip and knee flexors as well as a trace of knee extension and a trace of flexion and extension in the ankle $(1+$ in Lovett scale). From the first day after admission, a rehabilitation program was performed included: active exercises with upper limb resistance, active and passive exercises of the right lower limb, exercises according to neurodevelopmental methods (PNF), isometric exercises of active muscle groups and gradual passive uprighting (Fig.2). Due to the treatment of thrombosis in the left lower limb, passive exercises of that limb were contraindicated until the end of treatment. Active standing and learning of motion-related activities began after obtaining 


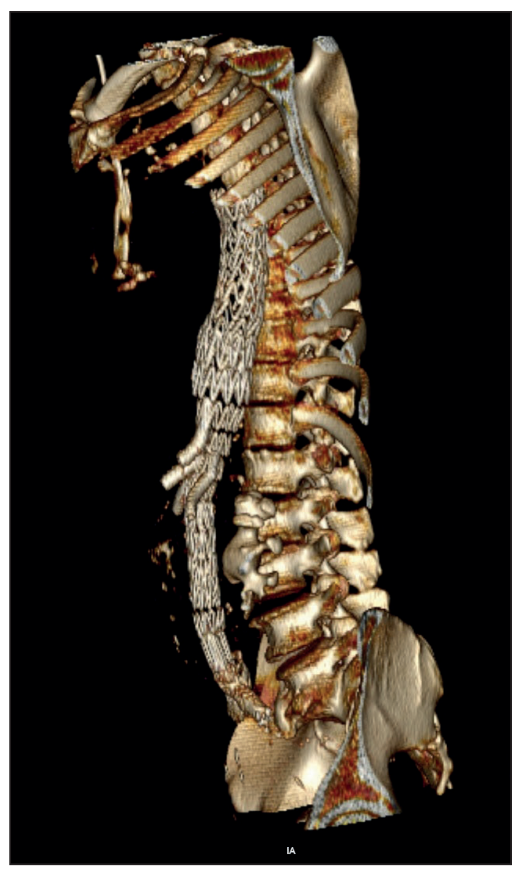

Fig. 1.3D computer tomography reconstruction of the graft.

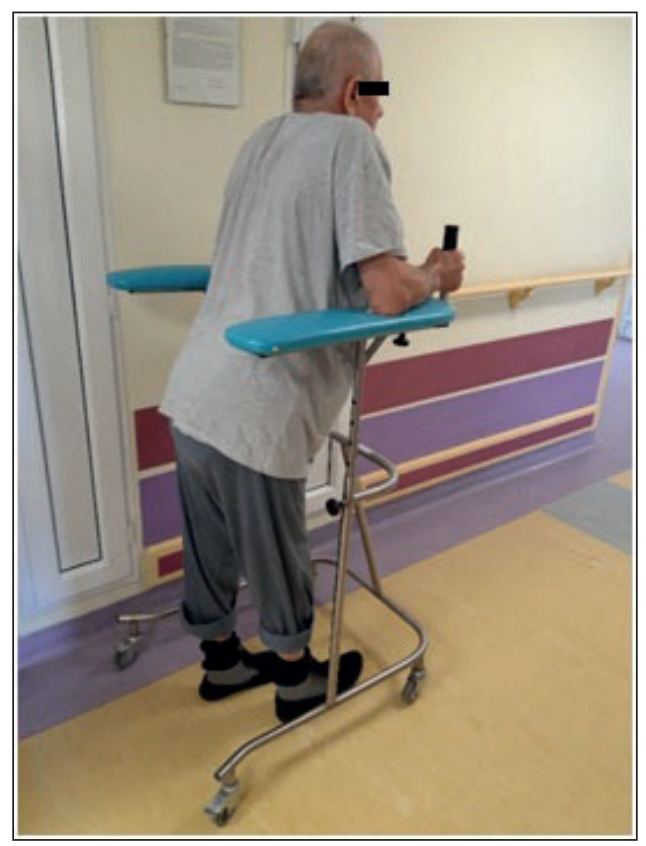

Fig. 4. Locomotive training with the help of a high balcony.

medical permission. Then the scope of physiotherapy was expanded to equilibrium exercises and prioprioception exercises in high positions, such as sitting and standing (Fig.3). After a period of 16 weeks of rehabilitation in the ward, the patient obtained a significant improvement in the strength of the muscles of the lower right limb (hip flexors 4, knee flexors 4, ankle flexors 3 in Lovett scale). The left lower limb was still functionally weaker (hip flexors 3, knee flexors 3, ankle flexors 2 in Lovett scale). The stabilization of the torso improved significantly, which

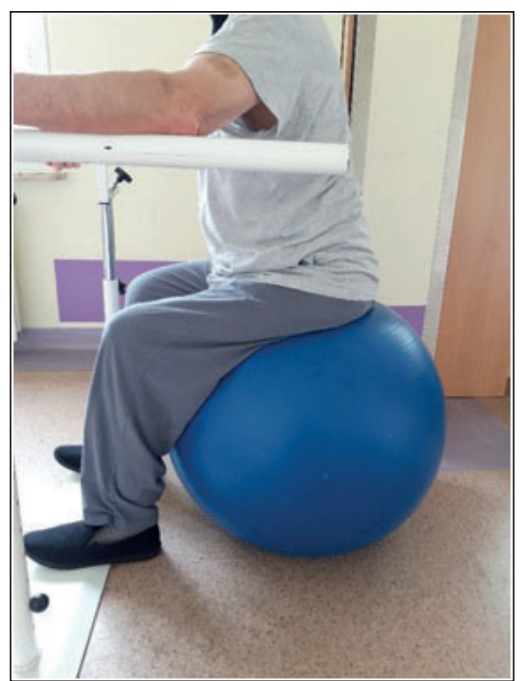

Fig. 3. Equilibrium exercises.
Fig. 2. Exercises according to the neuromuscular pathway (PNF) method.

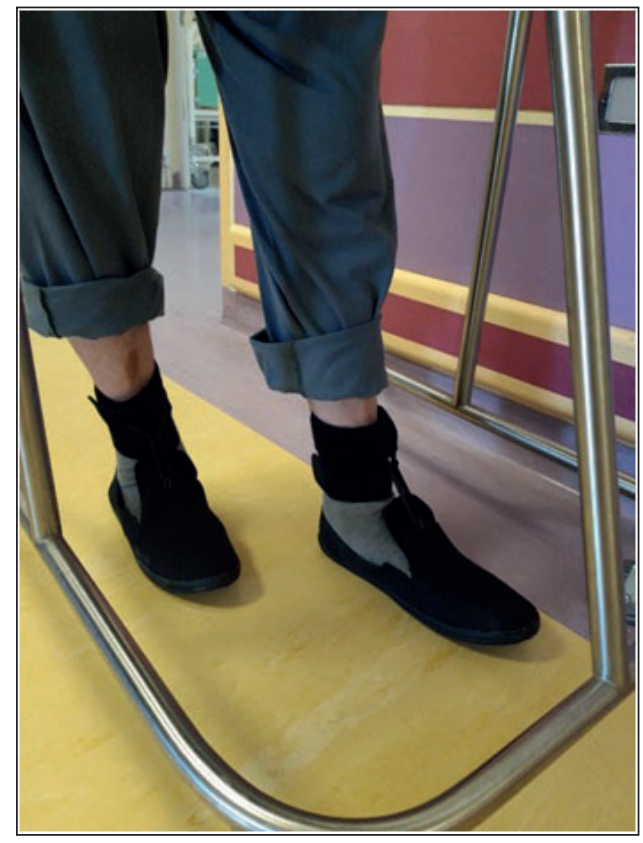

Fig. 5. Orthopedic equipment in the form of drop foot ankle orthosis.

enabled the patient to sit and stand independently with the help of a high walker or another person (Fig. 4). To protect the feet while walking, orthopedic equipment in the form of ankle drop foot orthosis was used (Fig. 5). When performing self-service activities, e.g. dressing, toilet, he no longer required the assistance of "third parties. On the Barthel scale he obtained 65 points. After 18 weeks of rehabilitation, the patient is able to cover a distance of 150 meters, still supplied with orthosis and high walker. $\mathrm{He}$ describes his state as satisfying. 


\section{CONCLUSIONS}

Factors increasing the risk of developing aortic aneurysm include: age over 55, male gender, family history of aneurysms, smoking, atherosclerosis, chronic obstructive pulmonary disease (COPD), hypertension, high blood cholesterol, ischemic heart disease.

Intravascular prosthesis insertion is a method increasingly used all over the world, enabling safe interference and repair of damaged vessels. Endovascular treatment allows therapy at an early stage of disease development. Complications of endovascular treatment include: leakage of blood into the aneurysmal sac, migration of the stent graft, stent graft breakdown or stent graft thrombosis [43] Jargiełło. A sharp increase in blood pressure during the stentograph expansion, poor placement associated with advanced atherosclerosis, can also cause a thrombus within the stentograph or lead to a fracture. Endovascular complications requiring long-term and comprehensive rehabilitation are stroke (4-6.7\%) or permanent or transient spinal cord stroke $(0-3 \%)[44,43]$. In order to avoid the above complications after surgery are used: the shortest aortic clamping time, not exceeding 60 minutes, avoiding drops in blood pressure during the procedure, monitoring of cerebrospinal fluid pressure, and if necessary cooling through epidural infusions of saline and the use of opioid receptor antagonists $[44,45]$.

Effective treatment of postoperative complications of aneurysms and aortic wall dysfunction as well as rapid recovery of the patient from before surgery depends on early and comprehensive rehabilitation. Physiotherapy should be carried out in the first postoperative days and carried out in a safe manner for the patient, under full medical supervision. Then we have a better chance of returning the patient to optimal mobility and independence in life.

\section{REFERENCES}

1. Crawford ES, Crawford JL, Safi HJ, et al. Thoracoabdominal aortic aneurysms: preoperative and intraoperative factors determining immediate and long-term results of operations in 605 patients. J Vasc Surg 1986;3:389-404

2. Svensson LG, Crawford ES, Hess KR, Coselli JS, Safi HJ. Experience with 1509 patients undergoing thoracoabdominal aortic operations. J Vasc Surg 1993;17:357-68.

3. Bjorck M, Bown MJ, Choke E, Earnshaw J, Florenes T, Glover M, Kay M, Laukontaus S, Lees T, Lindholt J, Powell JT, van Rij A, Svensjo S, Wanhainen A. International update on screening for abdominal aortic aneurysms: issues and opportunities. Eur J Vasc Endovasc Surg. 2015;49:113-11

4. LeFevre ML. Screening for abdominal aortic aneurysm: U.S. Preventive Services Task Force recommendation statement. Ann Intern Med. 2014;161:281-290.

5. Forsdahl SH, Singh K, Solberg S, Jacobsen BK. Risk factors for abdominal aortic aneurysms: a 7-year prospective study: the Tromso Study, 1994-2001. 2009;119(16):2202-2208.

6. Iribarren C, Darbinian JA, Go AS, Fireman BH, Lee CD, Grey DP. Traditional and novel risk factors for clinically diagnosed abdominal aortic aneurysm: the Kaiser multiphasic health checkup cohort study. Ann Epidemiol. 2007;17:669-678.
7. Svensjo S, Bjorck M, Gurtelschmid M, Djavani Gidlund K, Hellberg A, Wanhainen A. Low prevalence of abdominal aortic aneurysm among 65-year-old Swedish men indicates a change in the epidemiology of the disease. Circulation. 2011;124:1118-1123.

8. Kent KC, Zwolak RM, Egorova NN, Riles TS, Manganaro A, Moskowitz AJ, Gelijns AC, Greco G. Analysis of risk factors for abdominal aortic aneurysm in a cohort of more than 3 million individuals. JVasc Surg. 2010;52:539-48.

9. Lederle FA, Johnson GR, Wilson SE, Chute EP, Hye RJ, Makaroun MS, Barone GW, Bandyk D, Moneta GL, Makhoul RG. The aneurysm detection and management study screening program: validation cohort and final results. Aneurysm Detection and Management Veterans Affairs Cooperative Study Investigators. Arch Intern Med. 2000;160:1425-1430.

10. Alcorn HG, Wolfson SK, Jr, Sutton-Tyrrell K, Kuller LH, O'Leary D. Risk factors for abdominal aortic aneurysms in older adults enrolled in The Cardiovascular Health Study. Arterioscler Thromb Vasc Biol. 1996;16:963-970.

11. Quintana RA, Taylor WR. Cellular Mechanisms of Aortic Aneurysm Formation. Circ Res. 2019; 124(4):607-618.

12. Zhang $L$ and Wang $Y$. B lymphocytes in abdominal aortic aneurysms. Atherosclerosis. 2015;242:311-7.

13. Kugo H, Tanaka H, Moriyama T and Zaima N. Pathological Implication of Adipocytes in AAA Development and the Rupture. Ann Vasc Dis. 2018;11:159-168.

14. Police SB, Thatcher SE, Charnigo R, Daugherty A and Cassis LA. Obesity promotes inflammation in periaortic adipose tissue and angiotensin II-induced abdominal aortic aneurysm formation. Arterioscler Thromb Vasc Biol. 2009;29:1458-64.

15. Tsuruda T, Kato J, Hatakeyama K, Kojima K, Yano M, Yano Y, Nakamura K, Nakamura-Uchiyama F, Matsushima Y, Imamura T, Onitsuka T, Asada Y, Nawa Y, Eto T and Kitamura K. Adventitial mast cells contribute to pathogenesis in the progression of abdominal aortic aneurysm. Circ Res. 2008;102:1368-77.

16. Siu KL, Miao XN and Cai H. Recoupling of eNOS with folic acid prevents abdominal aortic aneurysm formation in angiotensin II-infused apolipoprotein E null mice. PLoS One. 2014;9:e88899.

17. Fanjul-Fernandez M, Folgueras AR, Cabrera S and Lopez-0tin C. Matrix metalloproteinases: evolution, gene regulation and functional analysis in mouse models. Biochim Biophys Acta. 2010;1803:3-19

18. Lareyre F, Moratal C, Zereg E, et all. Association of abdominal aortic aneurysm diameter with insulin resistance index. Biochem Med (Zagreb). 201; 28(3):030702.

19. Yajima N, Masuda M, Miyazaki M, Nakajima N, Chien S and Shyy JY. Oxidative stress is involved in the development of experimental abdominal aortic aneurysm: a study of the transcription profile with complementary DNA microarray. JVasc Surg. 2002;36:379-85.

20. Olsson C, Thelin S, Stahle E, Ekbom A, Granath F. Thoracic Aortic Aneurysm and Dissection: Increasing Prevalence and Improved Outcomes Reported in a Nationwide Population-Based Study of More Than 14000 Cases From 1987 to 2002. Circulation 2006;114:2611-8

21. Etheredge SN, Yee J, Smith JV, Schonberger S, Goldman MJ. Successful resection of a large aneurysm of the upper abdominal aorta and replacement with homograft. Surgery 1955;38:1071-81.

22. DeBakey ME, Crawford ES, Garrett HE, Beall AC, Howell JF, Howell JF. Surgical considerations in the treatment of aneurysms of the thoracoabdominal aorta. Ann Surg 1965;162:650-62

23. Coselli JS, LeMaire SA, Preventza 0, et al. Outcomes of 3309 thoracoabdominal aortic aneu- rysm repairs. J Thorac Cardiovasc Surg 2016;151:1323-38. 
24. Acher C, Wynn M. Outcomes in open repair of the thoracic and thoracoabdominal aorta. J Vasc Surg 2010;52:3S-9S.

25. Rigberg DA, McGory ML, Zingmond DS, Maggard MA, Agustin M Lawrence PF, et al. Thirty-day mortality statistics underestimate the risk of repair of thoracoabdominal aortic aneurysms: A statewide experience. J Vasc Surg 2006;43:217-22.

26. Roselli EE, Greenberg RK, Pfaff K, Francis C, Svensson LG, Lytle BW. Endovascular treatment of thoracoabdominal aortic aneurysms. J Thorac Cardiovasc Surg 2007;133:1474-82.

27. Eagleton MJ, Follansbee M, Wolski K, Mastracci T, Kuramochi Y. Fenestrated and branched endovascular aneurysm repair outcomes for type II and III thoracoabdominal aortic aneurysms. J Vasc Surg 2016;63:930-42

28. Volodos'NL, Karpovich IP, Shekhanin VE, Troian VI, lakovenko LF. [A case of distant transfemoral endoprosthesis of the thoracic artery using a self-fixing synthetic prosthesis in traumatic aneurysm]. Grudn Khir 1988;6:84-6.

29. 17. Parodi JC, Palmaz JC, Barone HD. Transfemoral Intraluminal Graft Implantation for Abdominal Aortic Aneurysms. Ann Vasc Surg 1991;5:491-9.

30. 18. Dake MD, Miller DC, Semba CP, Mitchell RS, Walker PJ, Liddell RP. Transluminal Placement of Endovascular Stent-Grafts for the Treatment of Descending Thoracic Aortic Aneurysms. N Engl J Med 1994;331:1729-34.

31. Szczerbo-Trojanowska M, Michalak J, Kobusiewicz W, et. al. Zastosowanie protez wewnątrznaczyniowych - stentów w leczeniu tętniaków aorty brzusznej. Pol Przegl Chir. 1999;71,5,494-500.

32. Kawamura S, Nishimaki H, Lin ZB, et.al. Emergent endovascular stent-graft placement to treat ruptured Stanford type B acute aortic dissection. J Vasc Surg 2004; 39(3):668-71.

33. Grabenwoger M, Fleck T, Czerny $M$, et al. Endovascular stentgraft placement in patients with acute thoracic aortic syndromes. Eur J Card Thor Surg 2003; 23:788-93.

34. Doss M, Balzer J, Martens S. Emergent endovascular stent grafting for perforated acute type B dissections and ruptured thoracic aortic aneurysms. Ann Thor Surg 2003;76:493-98.

35. Anderson JL, Berce M, Hartley DE. Endoluminal Aortic Grafting with Renal and Superior Mesenteric Artery Incorporation by Graft Fenestration. J Endovasc Ther 2001;8:3-15.

36. Hu Z, Li Y, Peng R, Liu J, Jia X, Liu X, et al. Multibranched StentGrafts for the Treatment of Thoracoabdominal Aortic Aneurysms. J Endovasc Ther 2016;23:626-33.

37. Hanna JM, Andersen ND, Aziz H, Shah AA, McCann RL, Hughes GC. Results With Selective Preoperative Lumbar Drain Placement for Thoracic Endovascular Aortic Repair. Ann Thorac Surg 2013;95:1968-75.

38. Conrad MF, Ye JY, Chung TK, Davison JK, Cambria RP. Spinal cord complications after thoracic aortic surgery: long-term survival and functional status varies with deficit severity. JVasc Surg 2008;48:47-53.

39. Eagleton MJ, Shah S, Petkosevek D, Mastracci TM, Greenberg RK. Hypogastric and subclavian artery patency affects onset and recovery of spinal cord ischemia associated with aortic endografting. JVasc Surg 2014;59:89-95.
40. Wynn MM, Acher CW. A Modern Theory of Spinal Cord Ischemia/Injury in Thoracoabdominal Aortic Surgery and Its Implications for Prevention of Paralysis. J Cardiothorac Vasc Anesth 2014;28:1088-99.

41. Tanaka H, Minatoya K, Matsuda H, et al. Embolism is emerging as a major cause of spinal cord injury after descending and thoracoabdominal aortic repair with a contemporary approach: magnetic resonance findings of spinal cord injury. Interact Cardiovasc Thorac Surg 2014; 19:205-10.

42. Greenberg RK, Lu Q, Roselli EE, et al. Contemporary Analysis of Descending Thoracic and Thoracoabdominal Aneurysm Repair: A Comparison of Endovascular and Open Techniques. Circulation 2008;118:808-17

43. Jargiełło T, Sojka M, Wolski A, et al. Implantacja stentgraftów u chorych zzagiętymi szyjami tętniaków aorty brzusznej - planowanie zabiegów, wyniki i powikłania. Post Nauk Med 2012;25:5.

44. Kulesza J. Ocena skuteczności i bezpieczeństwa wewnątrznaczyniowego leczenia za pomocą stentgraftów chorych ze schorzeniami aorty piersiowej. Rozprawa na stopień doktora nauk medycznych Katedra Radiologii Ogólnej i Zabiegowej Uniwersytetu Medycznego im. Karola Marcinkowskiego Poznań 2017

45. Pupka A, Pawłowska S, Szyber P, et al. Leczenie operacyjne i wewnątrznaczyniowe tętniaków aorty piersiowo-brzusznej z wykorzystaniem protez naczyniowych. Polim Med 2006;36, 1; 55-59

\section{ORCID and contributionship}

Magdalena Sobiech - 0000-0003-4923-5444 A,B,D,F

Karolina Turżańska - 0000-0001-7359-9622 D,E,F

Jaromir Jarecki - 0000-0002-6866-3850 ${ }^{D}$

Aleksandra Szopa - 0000-0002-7756-2904 ${ }^{D}$

\section{Conflict of interest:}

Authors declare no conflict of interest

\section{CORRESPONDING AUTHOR \\ Karolina Turżańska}

Chair and Department of Rehabilitation and Orthopaedics, Medical University of Lublin, Jaczewskiego 8, 20-954 Lublin, Poland tel: +48795833104 e-mail: karolina.turzanska@gmail.com

Received: 06.07 .2020

Accepted: 07.09 .2020

A - Work concept and design, B - Data collection and analysis, C - Responsibility for statistical analysis, D-Writing the article, $\mathbf{E}$-Critical review, $\mathbf{F}-$ Final approval of the article 
Magdalena Sobiech et al. 